Original research article

\title{
Green hope or red herring? Examining consumer perceptions of peer-to-peer energy trading in the United Kingdom
}

\author{
Kate Pumphrey ${ }^{\mathrm{a}}$, Sara Louise Walker ${ }^{\mathrm{a}, *}$, Merlinda Andoni $^{\mathrm{b}}$, Valentin Robu ${ }^{\mathrm{b}}$ \\ ${ }^{a}$ School of Engineering, Merz Court Building, Newcastle University, Newcastle Upon Tyne NE1 7RU, UK \\ ${ }^{\mathrm{b}}$ School of Engineering and Physical Sciences, Heriot Watt University, Edinburgh EH14 4AS, UK
}

\section{A R T I C L E I N F O}

\section{Keywords:}

Blockchain

Peer-to-peer energy trading

Decentralised energy system

Prosumer

Electricity trading

Social practice theory

\begin{abstract}
A B S T R A C T
Across the globe, electricity sectors have seen a relatively large increase in the number of installations of small renewable energy systems, leading to an interest in the potential role of the prosumer. These prosumers (producers and consumers of electricity) could help drive electricity sector transformation, but at present electricity trading is associated with a lack of control and power held by consumers. Peer-to-peer trading schemes between energy consumers are increasingly being reported in the trade press as a new way to empower consumers, especially since the advent of blockchain, an emergent technology that could facilitate the adoption of such schemes. Research to understand how and why electricity trading occurs has received little attention within literature thus far. In this study we investigated the existing elements of electricity trading. A total of 16 structured interviews with domestic consumers, business consumers, domestic prosumers and business prosumers were undertaken. All interviews identified ease of payment as a key theme for electricity trading (although we note that ease may be in tension with sustainability and greater awareness of energy-related environmental impacts). Consumer interviews also identified lack of engagement with the process of receiving energy, and cost, as key themes. Prosumer interviews identified positive associations with power, and personal and business image, as key themes. Therefore, it is recommended that these factors be incorporated into the user interface of blockchain systems, to potentially increase adoption for peer-to-peer trading.
\end{abstract}

\section{Introduction}

In recent years, a rising number of small, distributed electricity generators, such as micro wind turbines, photovoltaic (PV) systems and combined heat and power (CHP) generators, have been connected to the UK electricity grid, creating a more decentralized electricity system. For example, UK solar PV installations amounted to $32 \mathrm{MW}$ in January 2010 , rising to 13,137 MW by January 2019, of which $93 \%$ of installations are sub $4 \mathrm{~kW}$ capacity [1] (note that data from the Department for Business, Energy \& Industrial Strategy has been criticised for not including schemes that are unsubsidised). These distributed technologies are becoming more widely available, more cost effective (galvanised by support mechanisms such as the Feed-in-Tariff, see Fig. 1), and more efficient. This is allowing generation of electricity geographically closer to the consumer, reducing transmission and distribution losses, whilst empowering the consumer. This renewable generation, alongside technological developments in battery storage, smart meter roll out and adoption of demand-side measures to reduce electricity consumption, is providing the platform for a drastically different electricity system. Global trends in distributed generation [2] mirror that of the UK and so, to an extent, this case study can inform consideration of blockchain technology adoption for other parts of the world, particularly those with a deregulated electricity market. Consumers could help drive electricity sector transformation through greater involvement in electricity generation and trading, but electricity trading is associated with a lack of control and power held by consumers. Research to understand how and why electricity trading occurs has received little attention in existing literature.

In this different, future, electricity system, it may be that prosumers (electricity consumers who also produce) wish to trade their energy directly with other energy consumers in their local area. Several trials based on this emerging model of peer-to-peer (P2P) energy trading have taken place over recent years.

P2P electricity trading on a large scale is, in the future, increasingly likely to rely on blockchain or distributed ledger technologies. A key issue for use of blockchain-enabled systems is how consumers and prosumers will adapt to using such a new trading platform. Currently, purchasing electricity occurs in the background, requiring little thought

\footnotetext{
* Corresponding author.

E-mail address: sara.walker@newcastle.ac.uk (S.L. Walker).
} 


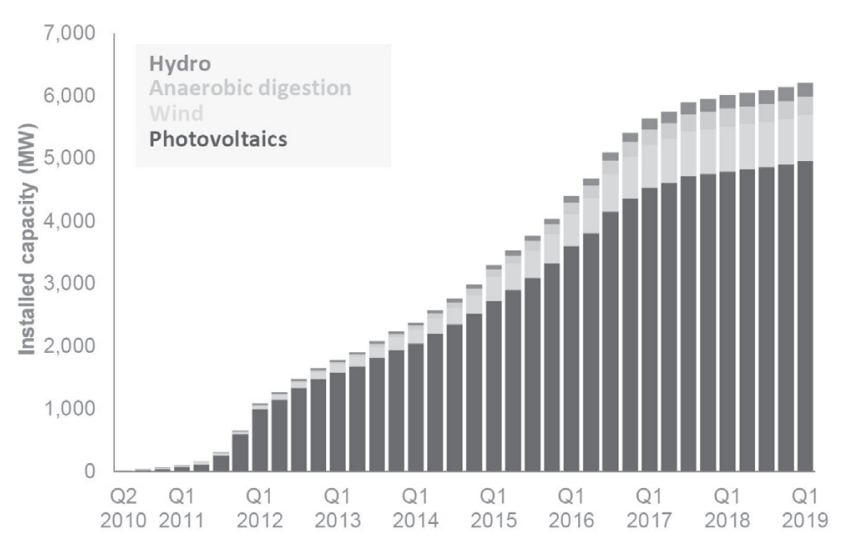

Fig. 1. Cumulative installed capacity registered under the Feed-in-Tariff scheme, UK, 2010 to 2019 [1].

on a day-to-day basis [3]. Persuading consumers and prosumers to change from current electricity trading mechanisms could pose a challenge and inhibit adoption of P2P trading via blockchain.

This study aimed to investigate social practices underlying current electricity trading used by consumers and prosumers, with the goal of identifying how blockchain user interfaces could be improved to increase adoption of peer-to-peer trading. The UK is used as a case study in this instance.

The overarching research problem was structured into two key objectives. Firstly, we aimed to investigate social practices underlying current electricity trading mechanisms, through structured interviews with a small number of domestic and non-domestic consumers and prosumers in the UK. The interview questions were structured in order to examine the social practices underlying electricity trading. Analysis then considered how electricity trading mechanisms were shaped by, and formed contexts within which they were used, and how energy demand, supply and trade were realized. Secondly, we built on our findings to make recommendations on how the user interface of a blockchain-enabled system could be adapted to improve adoption of peer-to-peer electricity trading. This drew on conclusions from the analysis and suggested how blockchain might integrate within the existing social practices identified, and how it may require new social practices, and therefore how blockchain and P2P trading could create change within energy trading.

A better understanding of how these everyday practices involved with electricity trading are habitually and typically performed will enable an improved understanding of how blockchain could be adapted to fit within or create a change in current practices, as well as the behaviours and attitudes that are incorporated within these

\section{Literature review}

Electricity produced in a centralised system has dominated electricity supply in the UK and many other countries for much of recent history. Centralised electricity systems have recently been subject to critique by scholars advocating for a decentralised electricity system $[4,5]$. This critique has been driven by several factors including climate change, energy security and technological advancements.

Four main advantages of decentralised energy systems have been noted in existing literature: the ability to produce electricity with low carbon emissions [6-8]; the ability to reduce the need for high capital investments for upgrades $[9,10]$; the ability to enable energy independence and security $[2,11,12]$; and the potential to enhance social cohesion $[13,14]$.

The implementation of distributed generation enables the formation of microgrids at the neighbourhood scale, which Adil and Ko [15] argued disrupts the traditional vertical format of energy services from utilities. The authors outlined several different models to organize new utility-consumer relationships ranging from consumer control and ownership to a public or private energy company controlling the system remotely. However, with all these configurations, the common trend that was acknowledged was the importance of the prosumer as a key player, and growth in end-user's choice and empowerment $[4,16,17]$.

The definition of energy prosumer varies, but a general definition is; consumers who also produce, trade, sell or store energy, associated with electricity mainly, although sometimes also with transport and heating [18]. Drawing on Schwartz's [19] work, Kotilainen and Järventausta [20] undertook an interesting study to discover motivations behind consumer's decisions to become prosumers, recognising a combination of intrinsic and extrinsic factors, including environmental conscience and financial motivations. Frey [21] drew a similar conclusion, and suggested consumers act on environmental values, but only if cost is not high.

Currently, in the UK, electricity produced through distributed generation can generally only be sold to a licenced supplier. However, several articles recognised that reduction in incentives such as the feedin-tariff (FIT) in the UK has slowed growth of prosumer numbers, as producing electricity becomes less economical $[22,23]$. Consequently, numerous articles argued that creation of an alternative energy market, which allows prosumers and consumers to trade with each other and that facilitates a balance within the community of generation and consumption, is of vital importance $[23,24]$. Thus far, studies investigating peer-to-peer electricity trading have largely focused on its socio-economic impact, including Giotitsas et al. [25] who examined the impact of electricity trading technologies on global socio-economic structure. However, this neglected local scale impacts, investigated by Long et al. [26], who addressed benefit to communities of P2P electricity trading being organized as a single entity, arguing this would lead to reduction in community energy costs. Zhou et al. [27] proposed a performance evaluation mechanism for P2P energy sharing and highlighted the potential of such schemes in reducing energy bills and incentivising demand response. Liu et al. [28] proposed a P2P energy sharing scheme with demand response and dynamic pricing coordinated by a central virtual entity. Spasova et al. [29] focused on trading within microgrids with heterogeneous types of renewable energy resources. Morstyn and McCulloch [30] proposed a P2P energy trading scheme where prosumers may have heterogeneous preferences on their energy usage. A comprehensive review on P2P energy trading schemes can be found in Abdella and Shuaib [31] and Zhang et al. [32].

Several trials based on the emerging model of peer-to-peer (P2P) energy trading have taken place over recent years. For example, in the UK, Piclo allows consumers to choose a renewable energy generator from which to receive their energy, linking generators and consumers [32]. In other trials, blockchain-based platforms have been used to enable P2P energy trading schemes. In the USA, LO3 Energy developed a microgrid where energy prosumers could trade solar energy surplus directly with their neighbours [33]. In Australia, Power Ledger developed a local residential marketplace for electricity trading between prosumers and consumers [34].

Blockchain is one of several digital ledger platforms that could be used for P2P applications. It consists of a growing list of blocks (records) secured through cryptography. A block contains transaction data, a timestamp and the cryptographic hash of the previous block, thereby new blocks are linked to previous blocks, forming an immutable record of events and their chronological order. This makes the blockchain a distributed ledger, managed via a P2P network of computers who are responsible for the validation of transactions, as opposed to centralised ledgers managed by a single, trusted authority node. The blockchain was originally made for trading Bitcoin, a digital currency, but since, this design has inspired other applications, including P2P energy trading.

Blockchain technology has been the focus of many recent studies. Andoni et al. [35] provided a comprehensive review of blockchain's 
potential in various applications in the energy sector. Johnson et al. [36] put particular emphasis on the innovation that blockchain could bring to distributed electricity networks. Mihaylov et al. [37] were one of the first to consider blockchain's use in electricity markets, and focused on cryptocurrency, proposing use of NRGcoins to trade renewable energy. Green and Newman [38] instead considered grouping communities into self-sufficient citizen utilities, and argued blockchain makes microgrids stronger, as it fosters trust between agents. Other works gave emphasis on the network operator side and simulated P2P local energy marketplaces with power flow simulations as seen from the grid's perspective [39,40]. Luo et al. [41] proposed an agent-based and blockchain solution for trading between prosumers. Local scale impacts of energy trading were investigated by Long et al. [26] who found benefit to communities of peer-to-peer electricity trading when organized as a single entity, arguing this would lead to reduction in community energy costs. Park and Yong [42] investigated the business model aspects of peer-to-peer electricity trading, and identified that further dissemination of renewable and internet technology would be vital. Coelho et al. [43] drew similar conclusions, outlining the importance of integrating renewable technology into networks. Morstyn and McCulloch [30] highlight the benefit of P2P for energy trading as enabling the prosumer to have control over setting the terms of the transaction, and delivery of the goods.

Although the potential of blockchain within electricity markets is undeniable, prior literature also identifies a number of problems that could act as barriers to further implementation.

To achieve consensus in a distributed blockchain network, it is possible to create mechanisms such as Proof-of-Work [44], which have been critiqued as being energy-intensive [45]. In addition to the energy-intensity of blockchain processes, Beck et al. [46] acknowledged that time taken for requests to be processed presented a barrier to the acceptance of the technology, confirmed in work by Yli-Huumo et al. [47]. Lim et al. [48] identified breaches of security occurring in Bitcoin. Along with these challenges is lack of knowledge about the technology. Gao et al. [49] found that participants who did not use blockchain claimed they were not able to do so as they lacked technical knowledge. Swan [50] also suggested lack of experience with decentralised mechanisms may inhibit use of such technologies.

\section{Theory}

In this paper we aim to better understand how everyday practices that can influence electricity trading by individual prosumers are typically performed. This will then enable us to reflect on how blockchain-based P2P electricity trading could be adapted to fit within or create a change in current practices. We therefore present a short section on social practice theory.

A theoretical framework based on practices has developed over the last 40 years, originating with work by Bourdieu and Giddens, with more recent development of the theory by Schatzki, Warde, Reckwitz, and Shove and Pantzar, a summary of which can be found in GramHanssen [51]. Social practices have been described as routinized behaviour "in which bodies are moved, objects are handled, subjects are treated, things are described and the world is understood" [52]. Further, Higginson et al. [53] describe social practice as "heterogeneous configurations of a range of different elements including physical and mental skills and competencies; technologies and infrastructures; and images, ideas and meanings".

Shove $[54,55]$ has been particularly influential in establishing social practice theory in relation to energy consumption, and has argued that energy consumption is not considered a practice in itself but is comprised of all the different practices that involve energy consumption (see also [53]). Shove and Walker [56] explored this further, suggesting that norms and social meanings are shared, and therefore practices follow common rules within a collective structure. Hargreaves [57] drew on Shove's work to understand practices as an integration of skills,

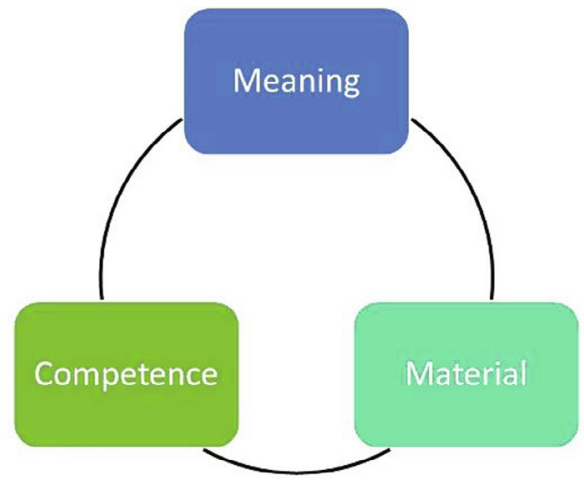

Fig. 2. Three component Social Practice Theory [59].

images and materials, which emerge and die when links between these elements are broken, re-made and replaced, and highlighted how this can explain the adoption of sustainable behaviour, as links between elements are re-made in ways that are more sustainable, leading to emergence of new practices. However, elements that constitute practices are different within different articles. For example, Gram-Hanssen [58] presented four elements, including institutionalised knowledge, engagements, embodied habits, and technologies. This is in contrast to the three-element model proposed by Shove et al [59] represented in Fig. 2. This showed there is a variety of interpretations of social practice theory. The variety of interpretations is also argued by Smale et al. [60] who identified several teleoaffective structures, including economy, sustainability, comfort, autonomy and safety. They argued that practices are motivated and orientated towards a mix of these teleoaffectives, which vary from household to household, and suggested these teleoaffective structures allow a more effective interpretation of social practice theory within which emotions occupy a more important role. Higginson et al. [53] and Southerton [61] presented an interesting analysis of practices and their relationship to temporalities, highlighting the uncertainty surrounding this, with some temporalities configuring practices. Rosa [62] acknowledged the emergence of the $24 / 7$ society resulting in acceleration of everyday life, but proposed that some practices shaped temporalities, consistent with Shove's [55] argument that practices occupy temporal locations.

Previous work has applied socio-technical approaches, including social practice theory, to elements of energy trading or prosumer/ consumer energy behaviours. Palm [63] used semi-structured interviews to identify perceived barriers for Swedish households to adopting PVs and becoming prosumers. High costs, lack of regulation, and administrative requirements, were identified as common barriers. Similarly, Inderberg et al. [64] investigated prosumer numbers and their correlation with economic incentives, regulatory requirements, and information practices alongside an installer market. This case study approach identified similar trends in stages of prosumer development across three European countries. Brown et al. [65] conducted nine semi-structured interviews with industry representatives to investigate the components of business models for prosumers, including a peer-topeer business model. They concluded that new business models for prosumers "often involve relinquishing various forms of control over prosumer energy systems". Sovacool et al. [66] found, based on a systematic literature review, that the smart meter implementation program in the UK was a barrier to the development of decentralised, prosumer-based energy systems. Gram-Hanssen [67] used social practice theory to evaluate appliance standby consumption. The author held in-depth interviews with ten households, and identified knowledge, engagement, and technologies and material structure that then framed understanding of changes in behaviour towards standby consumption. Palm and Reindl [68] also used the elements of social practice theory routines, technology, meaning and knowledge - to evaluate the practice of design of energy efficiency retrofit. They conducted thirty interviews, 
and found that inertia in the practice of planning and design led to reduced efficacy of energy efficiency targets. The inertia was particularly felt in the aspect of knowledge, where interviewees discounted new knowledge or excluded certain knowledge sources. Higginson et al. [53] argued that energy consumption was a "by-product of social practices such as cooking, showering, driving or laundry", and applied the three-component model of material artefacts, conventions and competences. Bisaga and Parikh [69] use social practice theory to explain the practices that rely on solar home systems for households in Rwanda.

Overall, social practice theory enables a more complex analysis of how and why practices are undertaken, and a better understanding of how such practices can be acquired. Therefore, this was the theoretical framework used in this study, and as such, it informed the type of questions used in the structured interview. It is common to use methods which enable the observation of the practice, or practices, in order to identify the meaning, competence and material. In this case, we do not directly observe the practices involved in electricity trading, and instead our questions probe what people say and think about what they do, targeted around the meaning, competence and material associated with the set of practices involved. This enables us to consider and reflect on the potential for blockchain systems to become part of the set of practices that comprise energy trading. However, we recognise the limitation of this method. What people say and think about what they do is reported outside of the practices and can be influenced by memory and by the interviewer/interviewee dynamic. What people think about a trading mechanism that they do not currently experience (blockchain) is also a limiting factor of the method, since this is likely to be influenced by their current meaning, competence and material in their existing set of practices. Furthermore, studying electricity trading as a discrete set of practices, which sit within a wider group of practices around energy use, is limited, since this "arguably prevents a consideration of how, both empirically and theoretically, we might recognize that the social is a field of embodied, materially interwoven practices" [70].

\section{Methodology}

\subsection{Interviews}

Interviews were selected as the method for obtaining qualitative data for this research. The questions aimed to extract a full description of interviewee's experience, asking about feelings, memories and emotions to investigate conscious reactions to electricity trading, as well as the situation in which electricity trading takes place. These structured interviews and set of questions were prepared prior to each interview, being similar for consumers and prosumers (please see Appendix A). However, exact questions asked varied in each interview, being tailored to the specific resident or business. This type of data collection method was chosen because it allowed more complex research questions to be discussed, which was important for investigating complex behaviours and attitudes [71]. It also avoided some issues of focus group work including potential for domination by individuals within the group, as well as pressure to reach a consensus.

We note there are limitations with interviews used for this research. Firstly, the views given are those of the individual, which should not be seen as wholly representative of the household (for domestic interviewees) or organisation (for business interviewees). Particularly for business interviewees, there may be some information which is excluded from the interview due to the perception of the interviewer as being outside the organisation, and the information being commercially sensitive or inappropriate to share. Further, the role of the interviewer can be influential in the way that interviewees interpret and respond to interviews. Interviews are a time-intensive method of qualitative data collection, involving the time-consuming task of preparing the research questions in a way that encourages the respondent to expand on certain subjects. Structured interviews are also costly to conduct if a certain distance had to be travelled to meet the respondent face-to-face, but by offering a choice of interview mediums, this problem was avoided [72].

The interviews took place via phone, skype, facetime, or face-toface, and took between 30 and $40 \mathrm{~min}$. The interviewee was given the option as to which method was preferable, so they felt at ease.

\subsection{Respondent selection}

The aim was to determine the practices involved with electricity trading mechanisms used by consumers and prosumers in the UK. Therefore, these two groups in the UK were selected as participants. There were no criteria for participants based on characteristics such as age, ethnicity, or gender, but participants were split into four categories: domestic consumers (DC), domestic prosumers (DP), business consumers (BC) and business prosumers (BP). The number of respondents in each category was not fixed, but instead determined by information gathered in each interview. When pattern analysis was no longer changing, no more interviewees were selected in this category. Sixteen interviews were conducted, comprising of six domestic consumers, two business consumers, three domestic prosumers and five business prosumers. A brief description of these interviewees is provided in Appendix B.

The qualitative nature of data collection resulted in a smaller sample to allow more time with each respondent, to gather more indepth information. This approach also required selection of respondents based on certain characteristics (consumer, prosumer, domestic, nondomestic) to best inform research [73]. This required a non-random approach to sampling participants, and therefore purposive sampling was selected. Gatekeepers were used to identify suitable residents or businesses in a community or group to contact, who had renewable technologies, or consumed energy, and were either able to provide contact details of these potential respondents or inform of a suitable way to contact them[73]. Snowball sampling was used to identify further respondents who met the criteria and were recommended by previous respondents as being suitable to contact. This method of sampling meant the respondent was linked to a trusted person, improving openness and cooperation [74]. Newcastle University ethics procedures were followed; informed consent was obtained prior to interview, interviewees could choose not to respond to questions at any time and withdraw from the study if they wished, and data arising from interviewees was anonymised. Interviewees are referred to in the study as $1-16$, and the category to which they belong is shown in Table 1.

\subsection{Processing of interviews}

Each interview was recorded on a Dictaphone and then was transcribed onto a Microsoft Word document. Transcribed documents were processed for word frequencies, which were then analysed to identify frequent words that provided an insight into the individual's experience. Word frequency was also identified for each group. The context within which frequent words were used, by members of the same group, was then analysed to identify similarities and differences within the group. Analysis of the context of frequent words for individuals and groups gave rise to identified themes. Themes were then analysed to discover those arising only in specific groups, or those present in all groups.

\section{Results}

This section presents findings from interviews undertaken. Sixteen interviews were conducted, comprising of six domestic consumers, two business consumers, three domestic prosumers and five business prosumers.

For each interviewee, a list of key words of interest were derived. By comparing key words across groups of interviewees, patterns were 
Table 1

Key word similarities and contrasts between groups.

\begin{tabular}{|c|c|c|c|c|c|c|c|c|c|}
\hline \multicolumn{10}{|c|}{ High frequency words } \\
\hline \multicolumn{10}{|c|}{ Domestic Consumers (DC) } \\
\hline DC 1 & Supplier & Renewable & Future & Pay & Service & Costs & Student & Bill & Debt \\
\hline DC 2 & Energy & Know & Supplier & Care & Guess & Bill & Pay & Easy & Local \\
\hline DC 3 & Energy & Supplier & Local & Expensive & Know & Easy & Relationship & Price & Tariff \\
\hline DC 4 & Energy & Meter & Easy & Compare & Trust & Time & Local & Process & Know \\
\hline DC 5 & Energy & Supplier & Rewarding & Easy & Price & Direct & Important & Know & Process \\
\hline DC 6 & Energy & Supplier & Community & Local & Price & Annual & Renewable & Pay & Process \\
\hline \multicolumn{10}{|c|}{ Business Consumers (BC) } \\
\hline BC 7 & Energy & Supplier & Research & Community & Price & Deals & Consortium & Time & Local \\
\hline BC 8 & Energy & Supplier & Local & Contract & Entitled & Deals & Price & Benefit & Involved \\
\hline \multicolumn{10}{|c|}{ Domestic Prosumers (DP) } \\
\hline DP 9 & Energy & Export & Electricity & Power & Time & Grid & Produce & Money & Scale \\
\hline DP 10 & Energy & Electricity & Understand & Power & Export & Capital & Time & Produce & Receive \\
\hline DP 11 & Electricity & Energy & Produce & Know & Feed-in-tariff & Reduce & Receive & Costs & Scale \\
\hline \multicolumn{10}{|c|}{ Business Prosumers (BP) } \\
\hline BP 12 & Energy & Building & Investment & Contract & Renewable & Bill & System & Money & New \\
\hline BP 13 & Energy & Contract & Building & Electricity & System & Investment & Policy & Reduce & Projects \\
\hline BP 14 & Energy & Feed-in-tariff & Lighting & Consumption & Behavioural & Generation & Contract & Renewable & Demand \\
\hline BP 15 & Energy & Time & System & Automatic & Export & Costs & Sell & Produce & Capital \\
\hline BP 16 & Residents & Scheme & Funded & Device & Collective & Service & Switching & Demand & District \\
\hline \multirow[t]{2}{*}{ KEY } & & All & & Consumer & & Prosumer & & Business & \\
\hline & & DC & & $\mathrm{BC}$ & & DP & & BP & \\
\hline
\end{tabular}

determined of common key words:

- across all categories of interviewees,

- across both categories of business interviewees,

- across both categories of consumer interviewees,

- across both categories of prosumer interviewees, and

- across multiple respondents within the individual categories of domestic consumer (DC), business consumer (BC), domestic prosumer (DP) and business prosumer (BP).

Patterns of key words are in Table 1 and are colour coded.

\subsection{Domestic consumer (DC)}

For DCs only, 'Easy', 'Pay', and 'Process' featured prominently among the key words used. This suggested that DCs valued the ease of the process of electricity trading. Secondly, there was emphasis placed on the action of paying, suggesting this was the practice most associated with electricity trading by DCs. However, although price was identified as important, switching was not amongst the key words for any of the DC respondents.

\subsection{Business consumer $(B C)$}

Table 1 displays one frequently sited word featured in the key word list of only BCs, 'Deals'. This occurred in both interviews undertaken. This suggested that BCs were more aware (than DCs) that they had other options in terms of price.

\subsection{Domestic prosumer (DP)}

Three common key words only featured in key word lists of DPs. These were 'Power', 'Receive', and 'Scale', which were all featured in at least two of the three DP key word lists. The use of 'Power' as well as 'Electricity' (featuring in all three key word lists), suggested that DPs were knowledgeable about electricity and power, and the difference between them through use of precise terms, which contrasted to consumers who only referred to 'Energy' when talking about electricity trading. The frequent use of 'Receive' also highlighted how the electricity trading mechanism used by prosumers, differed to consumers, as the action of receiving in return was important. 'Scale' was of importance to DPs as a factor that might influence likelihood of trading with others locally.

\subsection{Business prosumer (BP)}

Table 1 shows there are four frequently mentioned key words featured in the key word lists of BPs: 'System', 'Investment', 'Building' and 'Demand'. This suggested business prosumers used a more complex system to trade electricity, which included contracts, investment, management and matching demand, which is unnecessary for DCs and less complex for BCs and DPs. Finally, it is worth highlighting that 'Contract', 'Investment' and 'Demand' did not appear on the key word list of respondent BP 15, which was a notably smaller company. This could suggest that the bigger the company, the more complicated the process of electricity trading.

What follows are summaries of the interview responses, based on key areas of questioning, which are shown in the headings. Firstly, the interviews of domestic consumers (DCs) and business consumers (BCs) are presented, followed by interviews of domestic prosumers (DPs) and business prosumers (BPs). Where information is specific to a particular interviewee, they are referred to as DC1-DC6 for domestic customers, BC7-8 for business customers, DP9-11 for domestic prosumers and BP12-16 for business prosumers (as per Table 1).

\subsection{Domestic consumers (DC)}

\subsubsection{How the supplier is chosen}

The use of comparison websites was a common theme identified for almost all domestic consumers in the process to choose a supplier. DC 1 used Compare the Market, DC 2 used You Switch, DC 4 used Go Compare, DC 5 used Money Supermarket, and DC 6 used a 'money saving website'. They expressed the view that these sites were trustworthy because many people used them, and were easy to use.

"It was a fairly easy process, Go Compare is great for that sort of thing, because they assist you, and you can trust them because so many other people use them. It cuts down the time it would take to search yourself. And also I wouldn't be able to trust what the suppliers say on their websites because they're selling themselves, whereas having a third party means you get an experienced outside opinion." (DC4) 
The only instance where these sites were not used were when DC 2 first moved into a rented property and used a rolling contract, unaware that they were paying more than they could be, and DC 3 , who was retired, who was recommended a supplier by a friend. All those using the sites prioritized price, using them to make it easier to find cheaper deals.

The practice of switching suppliers was presumed by most respondents to be time-consuming and difficult with little saving, although several had not actually tried and therefore didn't know. For example, DC 5 presumed that switching would only result in a small saving and only trusted one company, DC 3 thought all suppliers were the same price and assumed it would be a hassle, and DC 2 thought the effort would not be worth it at first and was unaware that the price could be lower. For those that did switch, almost all used comparison websites to make the process easier.

The reliability of suppliers was identified as important by those respondents that had experienced problems with supplier reliability previously. DC 1 had been with a supplier whose customer service they felt was bad and bills came irregularly and DC 6's supplier increased the price without notice.

"Well, I am currently having major problems with my energy supplier as having renewed my annual contract at the price they quoted, the price increased by over $30 \%$ within 6 weeks. This was too late to withdraw from the agreement without a $£ 90$ penalty fee. So now I don't think this is fair, whereas I did before." (DC6)

This led to a change in approach, in that these interviewees reported they spent more time reading reviews of suppliers before committing. Those interviewees who were renting and had a short-term contract, stated they were more willing to use suppliers they had never heard of, such as DC 2 and DC 1 (before the bad experience with the supplier).

\subsubsection{How electricity is paid for}

All domestic customer interviewees said the process of paying for the electricity used and setting up these payments was easy and enabled through direct debit. This prompted some to say how this autonomy meant they didn't think as much about electricity usage. For example, DC 4 was not aware of using electricity until they got a smart meter, DC 5 did not 'think about it' and DC 3 commented on how they 'forget about it'. However, DC 4 highlighted how since they got a smart meter, they now regularly think about it, and link the costs of electricity to activities that use it.

"Yes, very easy, it's just direct debit straight out of my account. But that is also not great in a way, and before I had the smart meter too, because I just didn't have to think about the energy I was using, it was just there, so I'd use it, and not think about the impact that might have on the bill. Now I have a very different attitude though." (DC4)

Lifestyle differences and living contexts were found to result in different reported issues with purchase choices. DC 1 and 2 for example, indicated they cared less about reducing costs of electricity purchase, as they were living with others and so it wasn't purely their choice. Installation of a smart meter was also not their choice, as they did not own the house. They lacked full control of electricity trading.

\subsubsection{Switching to renewable electricity or local electricity}

When asked about interest in switching supplier in order to receive renewable electricity, interviewees said this was almost entirely dependent on price and cost. All DC interviewees said they would not use renewables unless they were the same price as the conventional cheapest source. Many liked the idea, but felt they could not afford it. This was the same for local generation. There was also a lack of knowledge by some who assumed renewables were always more highly priced, even though they had never actually looked. DC 1, 2, 3, 4 and 5 all held knowledge of the benefits of renewables but were held back by priorities of cost.

"Yes, I would definitely look for an environmentally friendly supplier....It depends on the cost difference. I'm happy to pay a small amount extra, probably up to $10 \%$ extra." (DC5) "I didn't actively go out and look for renewable suppliers but that one was being advertised on, Go Compare I think it was, and the deal sounded good, so I clicked on it and it told me they were suppliers of renewable energy. And I thought that sounded good to me, I mean I would say cost and price was most important to me, I would look at that first, but I've always like the idea of using renewables, so I suppose it was sort of an extra selling point, if you know what I mean. Renewable energy is definitely the future." (DC4)

\subsubsection{Reducing costs through energy efficiency}

All domestic customer interviewees said they undertook energy saving practices, altering the way they undertook activities and all with the priority to reduce costs. However, this only occurred if the changes were easy and did not change routines greatly. For example, DC 4 was willing to reduce "unnecessary" energy use, but when asked if they would change the order of practices in the day, was unwilling to change due to their busy lifestyle.

It was found that to start changing practices, electricity had to become a conscious thought to link electricity back to costs and provide motivation. For example, DC 3 had become more conscious of energy usage when retiring, but since then, they felt it had become natural. DC 4 became conscious when using a smart meter. DC 6 needed to keep costs down, but as this was part of their every day life, continually repeated, they felt it had become easy. DC 1 and 2 had different experiences, as although they both altered practices and agreed it became natural, experience differed due to sharing a house with others. DC 1 found that as all their housemates were very conscious of reducing costs, this made them feel they must fulfil their share of the responsibility and alter practices, motivating change. DC 2 on the other hand, felt their own alterations were futile as other residents did not alter practices.

"...because there are five of us in the house, we all have different attitudes to lots of different things, so it can be a little futile if you're trying to save energy and the others don't bother, and vice versa. So X is very good, he does things like turn off the microwave because the time light apparently uses energy, and stuff like that, very minute details, I always turn my lights off actually I am very good at that. I think Y probably is not so good, she doesn't turn her lights off and things like that..." (DC2)

Additionally, those renting (DC 1 and 2) felt it more difficult to undertake some energy saving actions, as no alterations could be made to the physical fabric of the house. The landlord retained the power to alter the building infrastructure. For example, DC 1 could not install a smart meter without the landlord's permission.

\subsubsection{Self-sufficiency and producing electricity to trade}

The consensus from domestic customer interviewees was that renewable technologies were too expensive to install. DC 3 and DC 6 also suggested that it would make the electricity trading process more difficult and time-consuming. However, when prompted further, this was based on assumptions and therefore there was a lack of knowledge of the export process of trading electricity.

"Ok and have you ever considered producing your own energy? Why did you decide against this? No I haven't, it's too expensive and too much hassle. Do you know anybody within your local community with a renewable technology? If it were possible, would you consider trading with them? No I don't, and I don't think I would consider trading with them either it sounds much more complicated than just using a supplier." (DC6)

\subsubsection{Trading locally and use of blockchain}

DC 1 and DC 3 were against trading with neighbours, both because they felt there would be an issue of trust. DC 3 suggested there would not be a proper, formal business relationship and that meant a neighbour couldn't be relied upon or held liable if something went wrong. They would 'feel bad' about complaining to a neighbour, but not to a business. DC 1 similarly suggested they went by the principle of 'never do business with friends' as trading money would lead to arguments 
and disputes and would become too personal. Both would rather the process of purchasing electricity was anonymous.

DC 6 would not consider trading locally because they felt it would be too complicated. DC 2, DC 4 and DC 5 would consider it if the price was the same and it was as easy as the current system. DC 4 liked the idea that they would be helping local people and money was not going to large corporations.

\subsection{Business consumers}

\subsubsection{How the supplier is chosen}

More complex systems were used to find a supplier for the business customer interviewees, which contrasts with domestic consumers. For example, BC 8 outsourced this process to another company (intermediary) who does a price comparison, and then presents them with a list of the best deals, as a different sort of contract is required that is harder to find using domestic-focused comparison websites. Similarly, BC 7 used a consortium (intermediary) to find the best deals. This complexity and need to outsource this process, removed from the businesses the full range of information and associated power to choose. Therefore, renewable suppliers were not considered unless stressed by the interviewee to their intermediary.

For BC 8, deciding between suppliers was 'time consuming' because it reflected on the employee if it went wrong, so more time was spent selecting the right supplier. However, BC 8 was also motivated to do so because it was part of the job that they were being paid for, more so than a domestic consumer. Reliability was considered as important by both BC 7 and BC 8 because a loss of electricity would lead to a loss of profits, and therefore it was more critical than for a domestic consumer.

Switching suppliers was not considered unless advised by the intermediary, as it was associated with effort.

"There are very good price comparison websites online [referring to domestic use], which are free, but with the size of consumption here, we need a different sort of contract, which is harder to find online, and suppliers that supply in bulk. I think the businesses we use to find the best deals actually have business relationships with suppliers, which means they can offer lower prices to their customers as a result of them recommending certain suppliers. I see yes that makes sense. And so would you describe this as an easy process? Have you encountered any difficulties? Difficulties, um, no I wouldn't say so. I mean it's fairly easy dealing with the business who advises us, and then setting up the contract with the supplier is fairly simple too. The only time consuming part is having to then decide between the suppliers, which is what I do personally. But this is part of my job, and I'm paid to do so." (BC8)

\subsubsection{Switching to renewable electricity or local electricity}

BC 8 felt pressure to consider renewables, because renewable electricity is important to customers, and therefore there exists a need to use renewables to maintain an appealing image. However, cost and price were most important, and if renewables are more expensive (an assumption), they decide not to purchase renewables.

BC 8 suggested the external business would be informed if they wanted to make renewable supply a priority and would benefit from their expertise and knowledge of the best renewable suppliers. Therefore, they put their trust in those with greater expertise.

"Well as a company we are very involved with environmental standards, as we offer ISO accreditation to other businesses. That means we are very aware of the trend that is occurring in the business world, towards becoming green and reducing consumption and everything else that comes along with this. So I suppose renewable electricity is important to a lot of our customers and there is certainly a movement towards this I would say. However, as a business we have to be very careful with costs, and particularly at this stage, we need to cut costs wherever possible. So higher prices renewable suppliers do not come up in the best deals that are identified by the external business. In future if we were doing particularly well, the business might sway towards paying slightly more for a renewable supply, but not at the moment." (BC8)

\subsubsection{Reducing costs through energy efficiency}

BC 7 had invested in efficient technology to reduce costs, because of a positive experience elsewhere. In terms of changing behaviours, equipment was used to adapt usage to better match demand, although only if this was easy to do and did not involve a lot of time and effort. BC 8 suggested that altering employee's practices in terms of electricity only worked if you linked it to pay. When it became part of the job, they felt they were receiving something in return. Before employees made this link consciously BC 8 felt they did not alter practices to reduce electricity because the increase in costs would not affect them personally.

\subsubsection{Self-sufficiency and producing electricity to trade}

BC 7 thought self-sufficiency wouldn't be possible due to their location within a conservation area, but when probed further, had no evidence or knowledge of whether this was true. BC 8 was also against it because of the capital costs of installing, and lack of incentives as the Feed-In-Tariff (FIT) was being withdrawn.

\subsubsection{Trading locally and use of a blockchain-enabled system}

BC 7 said the decision to trade locally would be made by the board of trustees. They felt they were powerless to decide at an individual level. This was a common problem also found in BC 8 and the BP group, as the decisions were not just down to an individual but numerous groups. BC 8 was concerned mostly about price, and so if local prices were lower, this would be the deciding factor. They also pointed towards ease as being important, as the system they have now is easy to use.

"Ok, and final question, do you know of any business or residents within the local community with solar panels? If it were possible, do you think XXX would consider trading with them? Well yes, if it was cheaper. It would give the business a good image and if prices are lower then great. But not if prices are higher. And, also, it would have to be fairly hassle free, because time is limited and changing from our easy system we have now would have to be justified. It would have to be as easy as it is now, or more so. “ (BC8)

\subsection{Domestic prosumers}

\subsubsection{Motivation to become a prosumer}

The main motivation reported regarding becoming a prosumer was to become 'green' and reduce $\mathrm{CO}_{2}$ emissions. For example, DP 9 stated they have a strong set of 'green credentials'. However, they thought financial incentives were also important, to allow a move to becoming a prosumer to be possible with the materials available (money and land). DP 11 specified that the FIT had made it feasible for them and was adamant that they would not have installed generation technology without it. However, whilst DP 9 and DP 10 stated that they would install without financial motivations, both actually installed at the time these financial support mechanisms became available. Access to the resource (wind, solar) was mentioned by both DP 9 and DP 10 as important in their decision to install. DP 11 had also been motivated to install by a friend who had expertise in combined heat and power (CHP).

“...I liked something about the beauty of it, and the simplicity if it, and that we knew that we were reasonably well off for wind where we are, it's not, it's not the most windy place, of course, we're not on a mountain or anything, but we checked because they had maps, we checked what our average speed was. I mean it was expected that we'd make a nice little return from it, nothing crazy, but you could justify it on the basis of economics. But I mean I had recently sold a business at that time and I think I was feeling that because I have a strong set of green credentials really, I wanted to do this anyway whether it even washed its face or not financially, so it was more of an environmental drive. That has definitely been the driver for me. So yeah, and I think it was much later that I though what else can I do, to further be more electricity efficient. We didn't put them on the roof because 
aesthetically that wouldn't have been right for our house, so the next option was to have them as a ground array." (DP9)

\subsubsection{Alteration of consumption to match supply}

No interviewees reported that they altered consumption to better match supply. DP 10 noted that they used electricity throughout the day because of a high base load, partly due to having no access to the gas grid. DP 11 noted that they didn't match supply and demand as they had supply available most of the time due to installing both solar and wind. Both DP 9 and DP 10 mentioned scale, which meant they had limited ability to alter consumption to match supply, as they did not produce enough.

"And do you try and match your consumption to what you produce...I think I do but I think I do it more or less by default. Because, our home receives solely electrical power, we don't receive any other input into the property, because we live on a farm and the farm is not on the gas grid. So we would either have to have bottled gas, so in fact, we rely purely on electricity. So we have a high base load, as we call it, which you might be familiar about, so I think really we do use electricity every hour of the day, so because of that I think were using by default. So I possibly export less than some just because of that fact." (DP10)

\subsubsection{Installation of batteries to facilitate trading}

DP 9 highlighted that money wasn't available for battery storage domestically, and stated they did not need to change the system once they had it. DP 10 and DP 11 said the scale of their system was too small to install batteries. DP 10 also had knowledge of batteries in their current state and it was this knowledge that put them off using them.

"And have you ever thought of installing batteries? I have, but I understand that it's quite capital intense. I think on a small scale, when the technology is not perhaps certain in terms of its performance to cost, I for example, you know the lifespan batteries, over what period, you know, their cycle time, all this, how many times they can cycle, whether they need to be fully charged or fully discharged, has kind of put me off a little bit, particularly because relating to what I said earlier, I have a high base load. I would be using more than what I would be producing anyway." (DP10)

\subsubsection{Exporting electricity}

All interviewees exported to their supplier, and therefore participated in two-way electricity trading. DP 10 said they exported half of what they generated. They also liked the fact that they used their own electricity more than they imported, seeing themselves as self-sufficient. DP 9 and DP 11 liked the automatic value of exporting in their contractual arrangement, as it meant they did not have to think about it. The knowledge they held of the ease of the system drew them to install.

\subsubsection{Trading locally and use of a blockchain-enabled system}

Lack of knowledge of blockchain technology had different contrasting effects. DP 9 and DP 11 expressed distrust and unsuitability of blockchain for their scale of operation. This contrasted with DP 10 who was enthusiastic and asked questions, wanting to increase their knowledge. However, all domestic prosumer interviewees mentioned importance of money and ease.

"if I was to put my investor hat on first, to answer your question, I would say that it sounds like something worth looking into, because why wouldn't you if there's an opportunity to gain a return by doing it. But the other hat is I'm not sure, for me personally, whether I would because I don't think the scale of what I do quite worth the effort involved." (DP9)

"Well I think that's an excellent idea. I don't understand it although I have heard of it. Although I didn't catch the exact phrase that you used. Did you say Blockscheme? Blockchain. That's it yeah. Oh excellent ok. Yeah so yeah I have heard of it. But Good Energy I was waiting to speak to them on the phone, in fact, and they said while I was waiting, all these messages kept coming through, and they said that on average people's energy travels about 2 and $a$ half thousand miles, I think I heard. Good Energy's energy only travels 4 miles, or within 4 miles. And I thought that sounds good to me, because the way I understand it, transmission loss, so over long distances I understand that over $10 \%$ of the power just gets lost. Is that what you understand? Yes, so if you're trading it on a much more local scale you won't lose quite so much electricity. Yeah quite. So green energy being traded locally is the ultimate scheme." (DP10)

\subsection{Business prosumers}

\subsubsection{Motivation to become a prosumer}

A mixture of views were expressed here for BPs motivation to become a prosumer. BP 12 and BP 13 installed renewables to meet targets set by the industry, and therefore felt pressure to become a prosumer. BP 14 installed to overcome the problem of an unreliable supply and the nature of their consumption meant reliability was critical. BP 15 and BP 16 installed because of high electricity bills and introduction of the FIT, which made the decision financially attractive.

"In total roughly we've got a thousand systems on domestic properties, and we've got about 50 bigger systems on public buildings, communal blocks and stuff like that, Civic Centre, schools, of those systems, most of them all the power's used on site, because the demand's generally bigger than the size of the roof that we have available. Um, some of them do spill into the grid and there's an agreement, but for the majority the power's used on site. The benefit of them, most of them were put in when the Feed-in-Tariff was much higher, contracts. And are you looking to expand that? I think probably at the moment we've done a thousand and 50 or so systems, we're probably not going to do much more in the short term because the feed in tariff has reduced dramatically in terms of the incentives. Costs have come up. What we'll do now is probably going to be done or reviewed as part of re-roofing works, that would be the opportune times to do it, because that would be the lower scaffolding costs. But yeah there's still a desire if you like to do further ones, but it's just economics." (BP16)

“...we've got the signs up so its good publicity, because normally you can't really shout about look how much more efficient this is compared to what it was, because there's nothing to show for it, but with the PV arrays you have got something to show for it. So that's definitely one element and we do publicise it. But also it just makes sense, that the key sense. We get good return on investment, about 10 years, that's what we work towards, so as long as its hitting those return on investment targets, then yeah we'll keep doing that." (BP12)

\subsubsection{Alteration of consumption to match supply}

BP 12, BP 13 and BP 15 stated they would not change energy consumption practices to better match supply, and did not see this as an effective way of reducing usage. Reasons included time, but also the main users of the business's buildings (tenants, for BP 12 and BP 13) did not own the buildings, and therefore would not personally experience the benefits of alteration of practice. Staff showed more responsibility if saving energy or altering consumption was made part of their job, such as the implementation of Green Impact Teams described by BP 13. The smaller the business, such as BP 15, the more the interviewee indicated they had responsibility and control. BP 15 claimed the high base load (like BP 10) reduced the need for them to undertake energy consumption changes. BP 14, however, was very enthusiastic about behaviour change to match demand, highlighting the reduced need for finance. They exported a significant amount, so they could see that shifting practices was more valuable to reduce costs.

"We have things like Go Green week to try and promote it but what we've found is that students in particular have very limited impact on energy use within the university. So um, best will in the world, we're not going to get students turning off the lights in classrooms when they leave, because they don't own that space. So they're not going to do it. It's only the student accommodation that you can only make sure they have an impact on that." (BP12) 


\subsubsection{Exporting electricity}

BP 12 and BP 14 were the only ones who exported significant quantities. BP 13 received no FIT and were not motivated to export. For both BP 12 and BP 13, the scale of the organisation made the electricity trading process more complex and therefore generation became one component of that. It was also harder for the technology to make as much difference in supplying demand. BP 14 was an interesting contrast and had managed to supply all demand during certain periods. This could be because of the nature of the business and the criticality of supply. Due to complexity, BP 12, BP 13, BP 14 and BP 16 brought in other specialised parties to deal with energy trading, including for export.

“...under the current contract, we've actually got a sort of locational contract. So all of the university's energy now, from very recently, is supplied from the new wind farm off Blyth, so it comes from the North East, and our consumption is matched to the generation from that wind farm, and we get the sort of, we can't guarantee that the electrons are the same electrons that were generated out at sea, it's all done by a contractual instrument, you know our consumption is matched to the consumption of that wind farm. So that's one aspect of energy trading, and as far as the wider energy trading goes, we use a company called the energy consortium who are our energy brokers and they buy our energy according to a risk management policy that we set, and we're in a basket essentially with lots of other universities, and we all tell the energy consortium, this is how much energy we need, you go away and buy it off the market and get us the best price you can." (BP13)

\subsubsection{Trading locally and use of a blockchain-enabled system}

BP 12 and BP 13 were particularly enthusiastic about P2P and blockchain-enabled systems, as investment in community initiatives and more sustainable investments were a norm required by the industry. BP 12's knowledge of it meant they recognised the benefits. However, BP 13 would only be interested if costs were lower as they would be buying not selling. For both BP 12 and BP 13, the rise of costs acted as an incentive to change to a different electricity trading mechanism. BP 15 said it would only work if routines were altered to spread out demand, due to everyone's practices operating in the same fixed routine. They suggested the mechanism might work if businesses and domestic households worked together, as they have different schedules of energy use and export. Both BP 15 and BP 16 suggested that scale and space were limiting factors for the adoption of this mechanism.

"So would that be anything you'd be interested in? For us, if there was the potential to buy off renewable schemes, I dare say yeah. If it's cheaper than we're getting off the grid then yes, we'd certainly consider that. We'd never, I can't see any situation where we'd ever be exporting. Our energy demand would always be too high...yeah I think it probably would be good to do that, rather than setting up an agreement with a big company, setting up a permanent power purchase agreement, yeah I think that it sounds like quite a reasonable thing." (BP12)

"The interesting thing about the model that you're talking about is that the university by perhaps investing some of its money in a model like that, the extent to which it could generate additional investment in renewable energy that otherwise wouldn't happen. And in doing that could assist communities to generate in that way and get all the benefits as part of that process. That's an interesting model. I know its talked about in the energy industry at the impact, the impact that Blockchain might have in blocking out the likes of the distribution companies, like Northern Power Grid, which of course is also another part of the non-commodity cost element of the bill that we pay, our transmission and distribution charges to the network operators, either national or local. So yeah those new models that are emerging where you almost contract directly with a producer that might be local and then pay a sort of conveyance fee to the operator, um, its something the university might be interesting in doing at some point, quite how we might dip our toe in that water I don't know." (BP13)

\section{Discussion}

The previous results section has provided contextual information on the most frequently occurring key words and relevant quotes from interviewees. In this discussion section we move to consideration of the themes identified, particularly the similarities and differences across groups of interviewees.

We consider the "doing" of electricity trading, and the ways in which materials, competence and meaning emerge as components of that. Materials are objects, infrastructure and tools that enable the practice. Competence is a skill or performance that enables the practice. Meaning can be considered the social or symbolic significance, or emotional connection, to the practice [75]. In the discussion, we particularly reflect on what the findings mean for the potential to move to a new way of electricity trading, using P2P technology.

\subsection{Domestic and business consumers}

For domestic and business consumers, the key word and context analysis enabled us to identify different associated practices for electricity trading, which included; searching for and choosing a supplier, setting up payments to the supplier, receiving electricity, consuming electricity and paying the supplier for electricity received (Fig. 3). However, each practice was made possible by the materials available, the competency to complete the practice, and the meaning prescribed to the practice. The practice was reinforced by these elements or altered if one or more of these elements change, and affected by the way in which practices relate to one another, as discussed by Shove.

The following themes emerged for the group of consumers interviewed.

A key theme identified for this group was ease of payment. The availability of direct debit made the process of payment automatic and therefore easy to use, reducing the need for consumers to be consciously involved in the practice of paying. However, this resulted in little conscious connection being made between consuming electricity and paying, and therefore using electricity was not associated with cost. Comparison sites also contribute to ease and speed to choosing a supplier for domestic consumers [76].

This may make it challenging to alter consumption practices to reduce electricity consumption, as there was little motivation to do so if

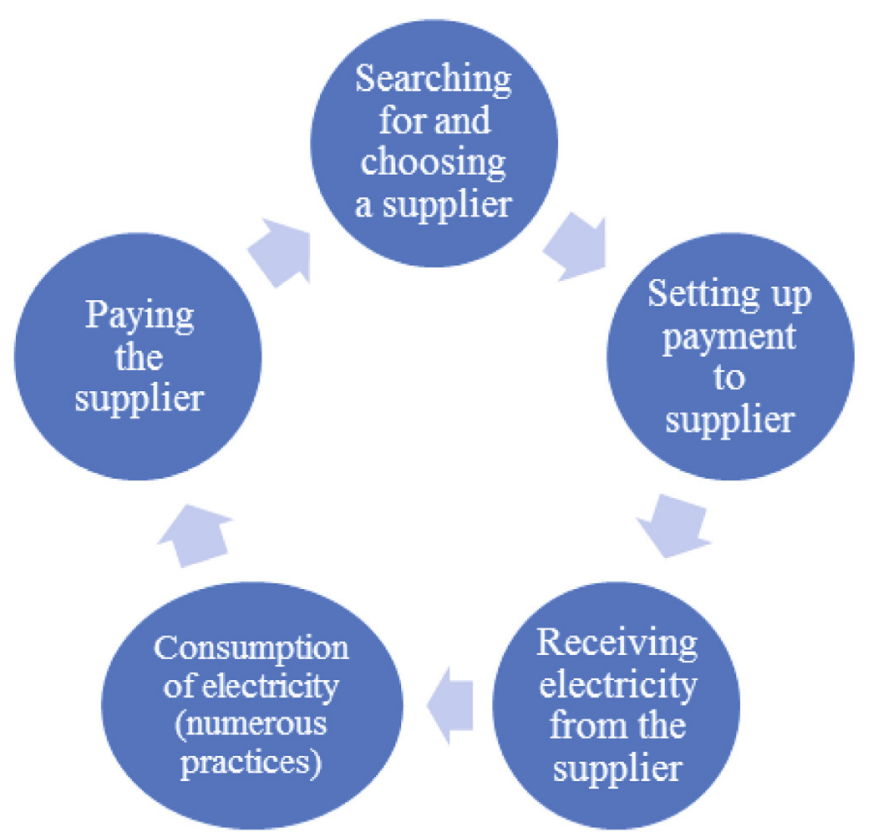

Fig. 3. Elements comprising consumer electricity trading mechanisms. 
costs (the main priority for consumers) were not connected to electricity use. This supported the evidence gathered from a host of studies looking at how electricity could be made more visible, and connected to the practice of paying, such as putting energy labels on appliances, providing more informative electricity bills, providing in-depth advice on energy, and smart meters [77-79]. However, those who experienced a change in lifestyle or negative event associated with paying the supplier, consciously connected the activity of consuming electricity to costs. Setting up payment to begin with was also considered an easy process by all consumers, possibly because the technology used to do so, was the same technology used for many other transactions, and therefore the infrastructure made use of existing knowledge and skills that had been developed from past uses of the technology. Both groups of consumers stated a desire for any peer -to-peer trading mechanism to offer a similar level of ease to them.

Here we identify, therefore, the payment infrastructure as the material element, and knowledge of the use of that infrastructure as the competence element, within the social practice framework. Although ease of use was considered an important factor, and technology was increasingly allowing electricity trading to become easier with less conscious involvement of the consumer, this trend may not be beneficial for the achievement of UK policies aimed at demand side reduction. Both domestic and business consumers expressed a lack of knowledge of the full benefits of switching suppliers. Switching was associated with effort and time with little difference in price, but few respondents had tried switching from one supplier to another, and therefore these associations were assumptions. Similarly, a study of switching in the Swedish electricity market identified lack of information about price differences led to formation of negative assumptions, which must be broken down before the practice can change and switching can occur [80]. What may be required in the future is an alteration of payment practices to increase the frequency by which the technology requires participation from the consumer. This supports Shove's [81] findings, where she argued that technological advancements and increasing efficiency, only help to maintain unsustainable and what is considered 'normal' ways of life.

Ease of use could perhaps be highly valued because of busy lifestyles and patterns of other activities within the day. This supported Rosa's [62] argument that temporalities configured practices, as the norm of daily time patterns include work practices during daytime hours, and home, domestic practices in the evening, and therefore electricity trading practices must fit into this temporal pattern.

A second key theme was lack of engagement with the process of receiving electricity. The perceived simplicity of the process of electricity being received by consumers was possibly due to limited knowledge about the details of the system. This may be partly because consumers had little to no involvement themselves (it didn't require any action from consumers), reinforced by their association of suppliers with the activity. The material and competence were relatively invisible enablers in the process of receiving electricity. This relates to work by Simmonds [82], which acknowledged how, within the current centralised system, it was suppliers who arranged contracts with distributers who then transferred electricity through the distribution network to the consumer. This also supports the argument that consumers in this system hold little power and authority, particularly over distribution, an argument addressed by Naus et al. [4]. However, the findings from this study showed that ease of use was highly valued, suggesting consumers did not necessarily want more power and control and were happy with their minimum involvement in the elements comprising electricity trading, which could pose a problem for the implementation of a more active, decentralised energy system. This contradicted scholars who stressed the benefits of a decentralised system, as none of these advantages were considered a top priority by these consumers $[2,7,9,13]$

Electricity supply only facilitated an associated practice (such as cooking, leisure) and therefore the practice itself was not directly associated with electricity use, particularly because electricity was not visible. Therefore, the consumption of electricity remained out of sight and mind, resulting in use and costs which were not realised until use had taken place, supporting Burgess and Nye's [83] conclusions that energy is doubly invisible, being physically invisible, entering buildings through hidden wires, and also as part of inconspicuous habits.

There is some speculation on whether consumers will pay more for a more reliable electricity supply service, with Huh et al. [84] suggesting consumers would pay $2.2 \%$ more on their electricity bill for a reliable supplier. However, our study contradicts these findings. Reliability was an important element for receiving electricity, although interestingly it was not consciously described as being highly valued by the consumer group. This may be because the group take the receipt of electricity for granted. However, to meet these expectations then reliability becomes important. Therefore, consumers had an unconscious expectation of reliability.

A third theme was cost. It was clear from the high frequency of words 'Price' and 'Costs' for all consumers, and the context within which these were used, that financial limitations were a highly influential factor on the process of selecting an electricity supplier, and for purchasing and receiving electricity. This meant that during the process of finding a supplier, those offering the cheapest prices were chosen above those offering quality, or a local or renewable source of electricity, supporting similar findings by Wilson and Price [85]. Financial resource is rarely discussed within research on social practice theory, although there has been some work on conspicuous consumption and the symbolic significance of that $[86,87]$, which is related to the social practice element of meaning. Further, Shove et al. [59] describe elements of the "material" for the practice of driving and remark on the financial implications of access to the material.

Financial limitations were also expressed as a barrier to uptake of the practice of local or renewable electricity purchase by interviewees. Additionally, the practice of producing and selling electricity was limited by financial materials available, preventing purchase of high capital cost renewable technologies. This was supported by Yaqoot et al. [88] who also found that high cost and lack of access to credit was a significant barrier to the adoption of renewables. Palm [62] also identified cost as a barrier to purchase of PV systems. Both domestic and business consumers lacked knowledge of the full benefits of switching suppliers. Switching was associated with effort and time with little difference in price, as discussed in the section on ease [80]. The increased pricing pressure on electricity supply firms can also lead to more competitive pricing, putting consumers in control as they can make a well-informed decision [89].

\subsection{Domestic and business prosumers}

The elements comprising the electricity trading mechanism for prosumers were in part like those of a consumer, including choosing a supplier, setting up payments to the supplier, receiving the electricity, consuming the electricity and paying the supplier for this electricity received. However, interview analysis showed prosumer's electricity trading mechanisms were also comprised of different elements. These included installing the renewable technology, setting up agreements with suppliers to receive payments, generating electricity, exporting this electricity, and receiving payment. Although none of the interviewees stored electricity, previous literature has identified this as a further element within prosumer's mechanism of trading electricity. It may begin to become a more common element if prices for this technology reduce (material barrier to adoption is lowered) [90]. Fig. 4 displays this set of elements that comprise prosumer's electricity trading.

The following themes emerged for the group of prosumers.

A key theme for this group was power and image. For domestic prosumers, the ability to export granted them greater power and control within the electricity system. This could reinforce current inequalities, 


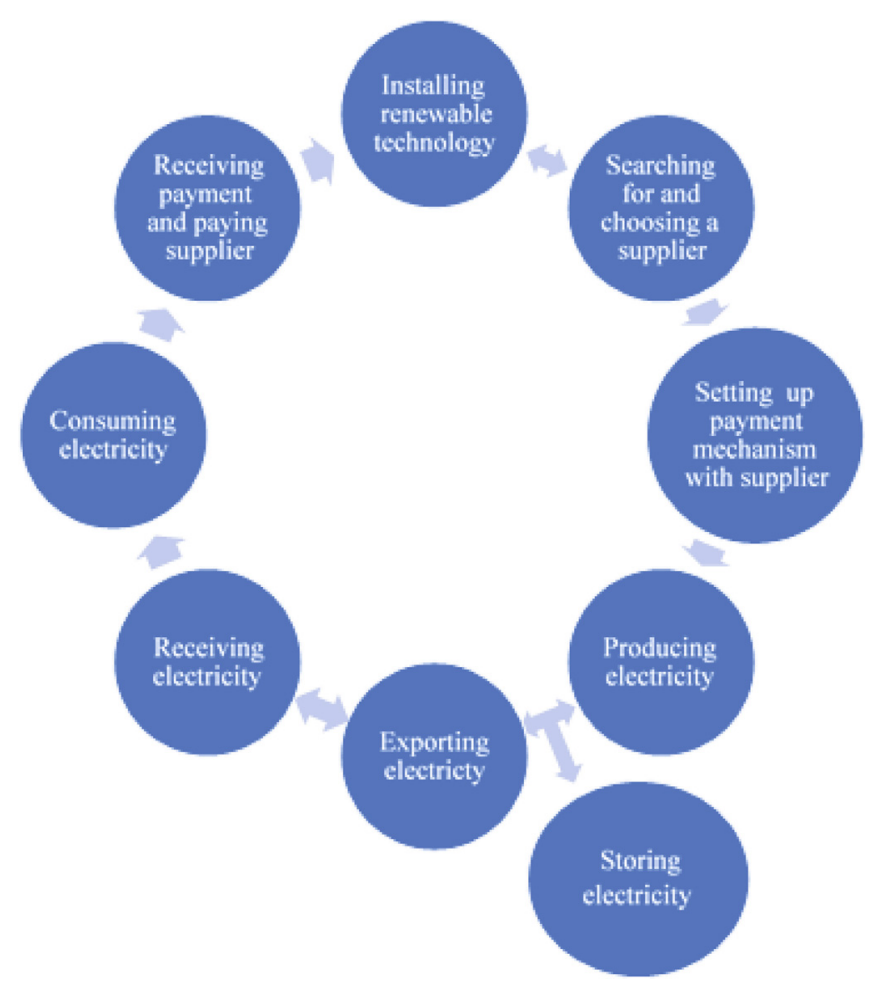

Fig. 4. Elements comprising prosumer electricity trading.

by enabling those with greater financial resources to be empowered. This potential problem is one overlooked by many scholars advocating for the rise of the prosumer $[16,17]$. For both domestic and business prosumers, scale was a limiting factor to realising increased personal/ institutional power in trading. Domestic prosumers were limited in scale of producing electricity, due to the limited financial materials available to invest in generation capacity, or limited space. This supported Balcombe et al.'s [91] argument that the significant occupation of space by renewable technologies is a barrier to installation. The larger size of businesses resulted in complex systems of electricity trading, and generation of electricity became just one (small) component in the system, less important in the overall scale of the business activity. This limited importance of trading was also reinforced by greater business demand, which made it less likely that renewable generation would cover demand, and therefore little surplus was likely to be exported. Further, lack of ownership of the building by BPs meant that users of the electricity (employees) did not feel responsible for alteration in electricity usage, and so there was little incentive for business demand reduction or demand-supply matching [92]. With regards image, both groups of prosumers stated the perceived benefit of being green, and being seen to reduce environmental impact, including portraying a better image to customers. Business prosumers had additional incentive if competitors were becoming prosumers, building on Khojastehpour and Johns' [93] argument that corporate social responsibility has a positive effect on reputation and profitability. Whilst DPs expressed "green" environmental drivers for their installation of generation, many also agreed that financial support was vital in decision making for the installation. Drawing and building on Frey's [21] work, we conclude that the practice occurred because of a combination of financial ability (facilitated through incentives which enabled economical operation and reduced payback period), and the meaning associated with installation of good environmental action and image.

A second theme for this group was ease. For domestic prosumers in particular, once installed, the autonomy of the generation and exporting system led to a reported perception of ease. The existing trading mechanism incorporated generation and export as well as import, and so everything was managed through one mechanism. The ease meant no conscious regular thought was required. This may result in a barrier to change; for example, lack of engagement in trading may be a barrier to reducing electricity consumption, particularly if prosumers feel they are already doing their part for the environment. Business prosumers also associate the process with ease, primarily because the practice was often outsourced to an external business. The complexity of electricity purchase, with the added process of selling, meant that greater expertise was required to carry out the practice, and therefore external specialist companies often carried out this practice, reducing engagement with trading for the businesses.

\subsection{A comparison of the consumer and prosumer group}

This work has identified two key areas of commonality across the consumer and prosumer groups: ease and cost.

EASE. Whether a business or domestic customer, consumer or prosumer, the perception of, and value of, ease of the current electricity trading mechanisms was apparent. This ease was in reference to setting up payments, making ongoing payments, and being paid for export. The processes of electricity trading make use of existing knowledge, skills and infrastructure in the UK, since consumers and prosumers use similar approaches for setting up and making ongoing direct debit payments for other goods and services.

COST. For the consumer and prosumer groups, cost and price were clearly identified as drivers for elements of electricity trading. The issue of price, or cost, was highlighted for choosing a supplier, paying for electricity, installing generation equipment to become a prosumer, purchasing renewable electricity, and trading locally. Given the nature of the product (electricity) does not enable suppliers to differentiate by product, price and associated services around the product become potential differentiators. Research has shown that, for products with identical features, price emerges as "the most important and almost exclusive comparison tool" [94].

This work has also identified a difference across the consumer and prosumer groups: power and image.

POWER AND IMAGE. For the prosumer group, meaning was attributed by interviewees to the opportunity to be self-sufficient, to be seen to be reducing environmental impact, and to play a role in the market as an exporter. This was not an emergent theme for the consumer group.

This contrast in energy trading practices between domestic and business consumers and prosumers emphasises the importance of understanding the situation within which electricity users live and work, and the ability to control their environment. This aligned with McMakin et al.'s [95] argument that practice-based intervention to encourage energy conservation practice adoption, should be tailored towards the specific situation.

What is clear in relation to the findings of these interviews is that prosumers and consumers have not identified that empowerment, demand response and control are important values to them, which is in contradiction to the value of distributed generation and blockchain systems proposed by Morstyn and McCullock [30], Green and Newman [38], Zhou et al [27] and Naus et al [4]. In fact, one could argue a direct tension between the theme of ease identified in this work, and the concept of empowerment.

\subsection{Summary}

To summarise, consumers and prosumers were found to undertake a similar set of practices involved with purchase of electricity, but prosumers also undertook additional, interlinked practices involving installation of renewable technologies, generation of electricity and export of electricity generated.

Technology allowed many of the practices to become automated, associating these with ease, and it was thought this removed the 
conscious link between costs of electricity purchase, and use of electricity. Financial limitations were also found to be a key barrier to adoption of alternative practices for both consumers and prosumers.

Practices of electricity purchase and export were significantly more complex for businesses than for domestic consumers, the former of whom often had insufficient knowledge to carry out these complex activities, resulting in export of electricity trading activities to an external organisation.

Finally, it was found the association of electricity trading with a positive image or meaning was a significant influence on the prosumer group. For example, domestic prosumers associated generating electricity with 'green credentials', and businesses associated purchasing or generating renewable electricity with corporate social responsibility (CSR). However, the financial resources available determined whether the technology purchase and installation could go ahead to achieve this image.

\section{Conclusions}

Analysis of the qualitative responses to interviews has enabled us to identify five key factors important to integrate into blockchain's user interface, to facilitate a change from the current electricity trading mechanisms towards a peer-to-peer system.

Firstly, ease and automation were identified as being of great importance, particularly for consumers when purchasing electricity. Current purchasing practices involve use of comparison sites for domestic consumers, and third parties for business consumers and prosumers. This increases the ease of the practice and allows it to fit within busy routines, resulting in electricity purchasing rarely entering conscious thought. For domestic prosumers, automation of exporting and importing electricity was key to the motivation to adopt renewables. Consumers and prosumers both valued ease and automation. Therefore, this finding could be applied to blockchain systems, ensuring transactions are automated (or partially automated), according to consumer preferences. Consumer preferences such as price, in the form of willingness to pay, or preferences that capture environmental or socioeconomic values of consumers, need to inform automated decisionmaking procedures that happen on behalf of consumers. A successful peer-to-peer (P2P) trading platform therefore requires the development of blockchain-based infrastructure, such as modified metering equipment, ICT equipment and trading platforms that can be reached via simple, intuitive and user friendly interface that facilitates ease of interaction with energy consumers. It should be noted, however, that there is tension between ease and the associated low visibility of electricity trading, and sustainable energy behaviours to reduce demand which could be better enabled by higher visibility of electricity trading.

Secondly, third parties were used to undertake practices involved in electricity trading because they provided knowledge to do so. This was because practices involving purchase and export of electricity in some cases were very complex, and so businesses lacked knowledge and skills required. Therefore, third parties may need to be involved in buying and selling electricity via a blockchain, to allow businesses to undertake the practices via this new mechanism. In a blockchain-based system, this role can be fulfilled by a trusted energy service provider, an aggregator or the trading platform developer, who would be responsible for the general system management and would take an advisory role to energy consumers and prosumers.

Thirdly, cost was found to be a top priority, due to limited financial resources. This prevented some consumers purchasing renewable energy, often because they perceived renewable electricity to be more expensive. Prosumers were also largely influenced by government incentives which enabled renewable energy system installation and energy export. For prosumers, withdrawal of the FIT scheme provides an opportunity for alternative methods of exporting and receiving payments to replace the current practice. For blockchain-based solutions to facilitate the change to current practices, costs would need to be lower for consumers than they are currently. This cost reduction would have to be substantial enough to make the perceived extra effort worthwhile. Information to develop consumers' knowledge of reduced costs would be important to create a positive connection with the practice for this new mechanism. Reduction in energy costs takes the shape of energy bills reduction for consumers and revenue generation for prosumers. Evidence from early trials and academic papers show this can be achieved in P2P trading schemes. However, one also needs to account for the overall costs of such schemes including the development costs for custom ICT equipment and software development, potentially outweighing the financial gains achieved by P2P trading.

Fourthly, for domestic customers trust was an important factor associated positively with current mechanisms. Domestic consumers expressed concern over a lack of accountability and therefore trust in a new mechanism that involved trading and relying directly on other members of the community. Third parties were found to increase trust in purchasing. Information that develops consumer's knowledge of blockchain for peer-to-peer trading, to associate the mechanism with trust, may be an important consideration to improve chances of adoption of blockchain. Transparency emerges as an important feature for consumer adoption as part of this issue of trust. However, this will need to be achieved without compromising private consumer data or commercially sensitive data.

Finally, it was found that image was an issue, with businesses increasingly subject to pressure within the industry to adopt CSR practices. Purchase of, or generation of, renewable electricity was associated with being 'green'. Blockchain technology's ability to facilitate the purchase and generation of renewable electricity, with the added benefit of helping local communities, could therefore appeal to prosumers and consumers. This could build meanings associated with blockchains as an opportunity for positive CSR or a positive 'green' image.

This study aimed to investigate social practices underlying current electricity trading used by consumers and prosumers, with the goal of identifying how a blockchain system's user interfaces could be improved to increase adoption of peer-to-peer energy trading. Those involved in the structured interviews had not previously experienced peer-to-peer energy trading and therefore these recommendations are based on perceptions, and not experience. We have identified five factors that will be important to incorporate into blockchain enabled peer-to-peer systems, to increase the likelihood of consumers and prosumers altering their existing electricity trading practices. This study also provided insight into influential elements that affect electricity trading. It expanded on literature using social practice theory, which has not previously considered electricity trading. It also contributed to the body of knowledge on peer-to-peer energy trading mechanisms and blockchain systems, which has primarily focussed on technical performance of blockchain solutions or business models for P2P in electricity trading. These findings would be relevant to locations beyond the UK with a similar structure to the electricity sector, since the findings are consistent with those of global studies of distributed generation $[2,9]$ and trends in social fabric in western societies [62].

\section{Declaration of Competing Interest}

The authors declare that they have no known competing financial interests or personal relationships that could have appeared to influence the work reported in this paper.

\section{Acknowledgements}

The authors acknowledge the support of the UK National Centre for Energy Systems Integration (CESI) under Engineering and Physical Sciences Research Council grant EP/P001173/1. 


\section{Appendix A}

Interview question framework.

Questions for Consumers

1 Who is your current energy supplier?

2. Can you talk me through the process you went through to find your current energy supplier? Why did you choose this particular one? Did you find this an easy process, if not, what difficulties did you encounter?

\section{How long have you been with this energy supplier?}

3.1. If short amount of time. What made you change supplier? Who was your previous supplier?

3.2. If a long amount of time. Why haven't you changed your supplier? Is it a difficult process to change supplier?

4 What value do you place on using a supplier that would supply renewable energy? Is the price more important than the type of energy?

4.1. If the price was the same would you be more bothered about the type of energy you are using?

4.2. How much of a problem is it to you that renewable energy suppliers generally charge higher tariffs?

4.3. Which tariffs are you on and why?

5. Does local generation factor in the decision to choose a supplier? Why/why not?

6. Can you talk me through the process you go through to set up and pay your energy bill? Would you describe this as an easy process?

6.1 If not why not?

7. Do you feel you are charged fairly for your energy usage?

8. Do you make a purposeful effort to reduce your energy usage?

8.1. If so, when did you start to do this? What motivated you to do so?

8.2. What do you do to reduce your energy usage?

8.3. Do you find this has changed the way you undertake certain activities? How does it alter the order of practises in your day?

8.4. Do you find performance of energy sustainability practises is rewarding?

9. Overall, how often would you say you thought about energy use?

10. Are you involved in your local community? To what extent would you support community energy projects and trading?

11. Have you ever considered producing your own energy? Why did you decide against this?

12. Do you know anybody within your local community with a renewable technology? If it were possible, would you consider trading with them?

\section{Additional questions for prosumers}

1. Which energy technologies do you currently have?

2. When did you install those?

3. Why did you choose these technologies?

4. What was your reason for installing them in the first place?

5 . Do you try and match your consumption to what you produce? How does the electricity generated by the technologies match your energy usage? Do you try to adapt your use of energy to fit with electricity generated?

6. Would you ever think of installing batteries to store the energy, would that be something you'd consider investing in?

7. Do you get generation tariffs? Do you get paid for what you use?

8. Who is your energy supplier, or who do you export it to? How would you describe your relationship with your supplier? How did you choose your energy supplier?

9. How would you describe the process of exporting electricity? Is it automatic? Do you need to think about it at all?

10. How quickly do you receive the money you get from the energy supplier?
11. How would you feel about using Blockchain to export and sell electricity to consumers in the future?

\section{Appendix B}

Characteristics of interviewees.

Domestic Consumers

DC 1 - Rented, Shared House, Semi Detached, University Student, Newcastle

DC 2 - Rented, Shared House, Second Floor Flat, University Student, St Andrews

DC 3 - Own House, retired single occupant

DC 4 - Own Family House, Single Parent with two children, Wrexham

DC 5 - Own Family House, middle aged couple, Newcastle

DC 6 - Own House, Terraced House, Middle Aged, Shropshire

\section{Business consumers}

BC 7 - Community Centre in Ponteland, runs daily classes, activities and fundraising events

BC 8 - Business Management Consultancy, based in Norwich

\section{Domestic prosumers}

DP 9 - Aged between 40 and 50, runs an outdoor education centre, solar panels on family home, ownership of house, Yorkshire

DP 10 - Aged between 30 and 40, Butcher, solar panels on farm barns and family home, ownership of house, Yorkshire

DP 11 - Aged over 60, ownership of house, Wales

\section{Business prosumers}

BP 12 - University employee, Northumberland

BP 13 - University employee, Newcastle, respondent was a member of the sustainability team

BP 14 - Hospital employee, Northumberland

BP 15 - Farm shop owner

BP 16 - Council employee, Northumberland

\section{References}

[1] Department for Business, Energy \& Industrial Strategy (2019). UK Energy in Brief. London: Department for Business, Energy \& Industrial Strategy.

[2] K. Alanne, A. Saari, Distributed Energy Generation and Sustainable Development, Renew. Sustain. Energy Rev. 10 (6) (2006) 539-558.

[3] T. Hargreaves, M. Nye, J. Burgess, Keeping Energy Visible? Exploring how Householders Interact with Feedback from Smart Energy Monitors in the Longer Term, Energy Policy 52 (2013) 126-134.

[4] J. Naus, G. Spaargaren, B.J.M. van Vliet, H.M. van der Horst, Smart Grids, Information Flows and Emerging Domestic Energy Practices, Energy Policy 68 (2014) 436-446.

[5] Bouffard, F. and Kirschen, D.S. (2008) Centralised and Distributed Electricity Systems. Energy Policy 36 (12): 4504-4508. Energy Policy 135: 110984.

[6] P. Droege, Renewable Energy and the City, Encyclopaedia Energy 5 (2004) 301-311.

[7] M.F. Akorede, H. Hizam, E. Pouresmaeil, Distributed Energy Resources and Benefits to the Environment, Renew. Sustain. Energy Rev. 14 (2) (2010) 724-734.

[8] J.A. Mathews, The Renewable Energies Technology Surge: a New Techno-Economic Paradigm in the Making? Futures 46 (2013) 10-22.

[9] P. Chiradeja, R. Ramakumar, An Approach to Quantify the Technical Benefits of Distributed Generation, IEEE Trans. Energy Convers. 19 (4) (2004) 764-773.

[10] W. El-Khattam, M.M. Salama, Distributed Generation Technologies, Definitions and Benefits, Electr. Power Syst. Res. 71 (2) (2004) 119-128.

[11] G. Walker, N. Cass, Carbon Reduction, 'The Public' and Renewable Energy: Engaging with Socio-Technical Configurations, Area 39 (4) (2007) 458-469.

[12] D.T. Ton, M.A. Smith, The U.S. Department of Energy's Microgrid Initiative, Electr. J. 25 (8) (2012) 84-94.

[13] G. Walker, S. Hunter, P. Devine-Wright, B. Evans, H. Fay, Harnessing Community Energies: Explaining Community Based Localism in Renewable Energy Policy in the UK, Global Environ. Polit. 7 (2) (2007) 64-82.

[14] G. Walker, P. Devine-Wright, S. Hunter, H. High, B. Evans, Trust and Community: Exploring the Meanings, Contexts and Dynamics of Community Renewable energy, 
Energy Policy 38 (6) (2010) 2655-2663.

[15] A.M. Adil, Y. Ko, Socio-Technical Evolution of Decentralized Energy Systems: A Critical Review and Implications for Urban Planning and Policy, Renew. Sustain. Energy Rev. 57 (2016) 1025-1037.

[16] T. Wang, Y. Gong, C. Jiang, A Review on Promoting Share of Renewable Energy by Green-Trading Mechanisms in Power System, Renew. Sustain. Energy Rev. 40 (2014) 923-929.

[17] Y. Cai, T. Huang, E. Bompard, Y. Cao, Y. Li, Self-Sustainable Community of Electricity Prosumers in the Emerging Distribution System, IEEE Trans. Smart Grid 8 (5) (2016) 2207-2216.

[18] Ford, R., Whitaker, J. and Stephenson, J. (2016) Prosumer Collectives: A Review. A Report for the Smart Grid Forum. New Zealand: Centre for Sustainability, University of Otago.

[19] S.H. Schwartz, Normative Influences on Altruism, Adv. Exp. Soc. Psychol. 10 (1977) 221-279.

[20] Kotilainen, K. and Järventausta, P. (2016) Understanding Prosumers' Intrinsic and Extrinsic Motivations to Become Active Participants in Smart Grid Innovation Ecosystem. IEEE PES Innov. Smart Grid Technol. Conf. Eur., Ljubljana, 9-12 October.

[21] B. Frey, Morality and Rationality in Environmental Policy, J. Cons. Policy 22 (1999) 395-417.

[22] Elliot, D. (2016) Renewable Energy in the UK: A Slow Transition. In: Shmelev S. (eds) Green Economy Reader. Studies in Ecological Economics, vol 6. Springer, Cham: 291-308.

[23] W. Tushar, C. Yuen, H. Mohsenian-Rad, T. Saha, H.V. Poor, K.L. Wood, Transforming Energy Networks via Peer to Peer Energy Trading: Potential of Game Theoretic Approaches, IEEE Signal Process Mag. (2018) 1-38.

[24] E. Mengelkamp, B. Notheisin, C. Beer, D. Dauer, C. Weinhardt, A Blockchain-Based Smart Grid: Towards Sustainable Local Energy Markets, Comput. Sci. Res. Dev. 33 (1-2) (2018) 207-214.

[25] C. Giotitsas, A. Pazaitis, V. Kostakis, A peer-to-peer approach to energy production, Technol. Soc. 42 (2015) 28-38.

[26] Long, C., Wu, J., Zhang, C., Thomas, L., Cheng, M. and Jenkins, N. (2017) Peer-toPeer Energy Trading in a Community Microgrid. IEEE Power \& Energy Society General Meeting, Chicago, USA: 1-5.

[27] Y. Zhou, J. Wu, C. Long, Evaluation of peer-to-peer energy sharing mechanisms based on a multiagent simulation framework, Appl. Energy 222 (2018) 993-1022.

[28] N. Liu, X. Yu, C. Wang, C. Li, L. Ma, J. Lei, Energy-sharing model with price-based demand response for microgrids of peer-to-peer prosumers, IEEE Trans. Power Syst. 32 (5) (2017) 3569-3583.

[29] Spasova, B., Kawamoto, D. and Takefuji, Y. (2018). Energy exchange strategy for local energy markets with heterogenous renewable sources. In 2018 IEEE International Conference on Environment and Electrical Engineering and 2018 IEEE Industrial and Commercial Power Systems Europe (EEEIC/I\&CPS Europe):1-6.

[30] T. Morstyn, M. McCulloch, Multi-class energy management for peer-to-peer energy trading driven by prosumer preferences, IEEE Trans. Power Syst. (2018).

[31] J. Abdella, K. Shuaib, Peer to peer distributed energy trading in smart grids: A survey, Energies 11 (6) (2018) 1560.

[32] C. Zhang, J. Wu, C. Long, M. Cheng, Review of Existing Peer-to-Peer Energy Trading Projects, Energy Procedia 105 (2017) 2563-2568.

[33] E. Mengelkamp, J. Gärttner, K. Rock, S. Kessler, L. Orsini, C. Weinhardt, Designing microgrid energy markets A case study: the Brooklyn Microgrid, Appl. Energy 210 (2018) 870-880.

[34] Power Ledger (2018) Power Ledger White paper. Available at: < https://web. powerledger.io/wp-content/uploads/2017/07/Power-Ledger-Whitepaper.pdf > , [Accessed 1 June 2018].

[35] M. Andoni, V. Robu, D. Flynn, S. Abram, D. Geach, D. Jenkins, P. McCallum, A. Peacock, Blockchain technology in the energy sector: A systematic review of challenges and opportunities, Renew. Sustain. Energy Rev. 100 (2019) 143-174.

[36] Johnson, L. P., Isam, A., Gogerty, N. and Zitoli, J. (2015) Connecting the Blockchain to the Sun to Save the Planet. Available at: https://ssrn.com/abstract $=2702639$ [Accessed 20 February 2018].

[37] Mihaylov, M., Jurado, S., Avellana, N., Van Moffaert, K., de Abril, I.M., and Nowe, A. (2014) NRGcoin: Virtual Currency for Trading of Renewable Energy in Smart Grids. 11th International Conference on the European Energy Market (EEM14), Krakow, Poland 28-30 May.

[38] J. Green, P. Newman, Citizen Utilities: The Emerging Power Paradigm, Energy Policy 105 (2017) 283-293.

[39] Coignard, J., Munsing, E., MacDonald, J. and Mather, J. (2018). Co-simulation Framework for Blockchain Based Market Designs and Grid Simulations. In 2018 IEEE Power \& Energy Society General Meeting (PESGM): 1-5.

[40] Hayes B.P., Thakur S. and Breslin J.G. (2018) Co-simulation of electricity distribution networks and blockchain energy trading platforms. Available at: < https://www.researchgate.net/publication/326812245_Co-simulation_of_ Electricity Distribution_Networks and Blockchain Energy Trading Platforms $>$ [Accessed 5 June 2019].

[41] F. Luo, Z.Y. Dong, G. Liang, J. Murata, Z. Xu, A Distributed Electricity Trading System in Active Distribution Networks Based on Multi-Agent Coalition and Blockchain, IEEE Trans. Power Syst. (2018).

[42] C. Park, T. Yong, Comparative Review and Discussion on P2P Electricity Trading, Energy Procedia 128 (2017) 3-9.

[43] V.N. Coelho, M.W. Cohen, I.M. Coelho, N. Liu, F.G. Guimarães, Multi-Agent Systems Applied for Energy Systems Integration: State-of-the-Art Applications and Trends in Microgrids, Appl. Energy 187 (2017) 820-832.

[44] Nakamoto, S. (2008) Bitcoin A Peer-to-Peer Electronic Cash System. Available at: < http://www.bitcoin.org > [Accessed 6 January 2018]
[45] O’Dwyer, K.J. and Malone, D. (2014) Bitcoin Mining and its Energy Footprint. 25th IET Irish Signals and Systems Conference and China-Ireland International Conference on Information and Communications Technology (ISSC 2014/CIICT 2014), Limerick, Ireland 26-27 June.

[46] R. Beck, J. Stenum Czepluch, N. Lollike, S. Malone, Blockchain - The Gateway to Trust-Free Cryptographic Transactions, Res. Papers 153 (2016) 1-14.

[47] Yli-Huumo, J., Ko, D., Choi, S., Park, S. and Smolander. K. (2016) Where Is Current Research on Blockchain Technology? - A Systematic Review. PloS ONE 11(10).

[48] Lim, I-K., Kim, Y-H., Lee, G-J., Lee, J-P., Nam-Gung, H. and Lee. J.K. (2014) The Analysis and Countermeasures on Security Breach of Bitcoin. In: Murgante B. et al (eds) Comput. Sci. Appl.- ICCSA 2014: 720-732.

[49] Gao, X., Clark, G.D. and Lindqvist, J. (2016) Of Two Minds, Multiple Addresses, and One Ledger: Characterizing Opinions, Knowledge, and Perceptions of Bitcoin Across Users and Non-Users. Proceedings of the 2016 CHI Conference on Human Factors in Computing Systems: San Jose, California, USA, 1656-1668.

[50] M. Swan, Blockchain: Blueprint for a New Economy, O'Reilly Media Inc, Sebastopol, 2015.

[51] K. Gram-Hanssen, Consuming technologies - developing routines, J. Cleaner Prod. 16 (11) (2008) 1181-1189.

[52] A. Reckwitz, Toward a theory of social practices, Eur. J. Social Theory 5 (2) (2002) 243-263.

[53] S. Higginson, E. McKenna, T. Hargreaves, J. Chilvers, M. Thomson, Diagramming social practice theory: An interdisciplinary experiment exploring practices as networks, Indoor Built Environ. 24 (7) (2015) 950-969.

[54] E. Shove, Comfort, Cleanliness and Convenience, Berg publisher, Oxford/New York, 2003.

[55] E. Shove, Beyond the ABC: Climate Change Policy and Theories of Social Change, Environ. Plan. A 42 (6) (2010) 1273-1285.

[56] E. Shove, G. Walker, What is Energy for? Social Practices and Energy Demand, Theory Cult. Soc. 31 (5) (2014) 41-58.

[57] T. Hargreaves, Practice-ing Behaviour Change: Applying Social Practice Theory to Pro-Environmental Behaviour Change, J. Cons. Cult. 11 (1) (2011) 79-99.

[58] K. Gram-Hanssen, New Needs for Better Understanding of Household's Energy Consumption - Behaviour, Lifestyle or Practices? Arch. Eng. Design Manag. 10 (1-2) (2014) 91-107.

[59] E. Shove, M. Pantzar, M. Watson, The Dynamics of Social Practice: Everyday Life and How it Changes, SAGE Publications Ltd, London, 2012.

[60] R. Smale, B. van Vliet, G. Spaargaren, When Social Practices Meet Smart Grids: Flexibility, Grid Management and Domestic Consumption in The Netherlands, Energy Res. Social Sci. 34 (2017) 132-140.

[61] D. Southerton, Habits, Routines, and Temporalities of Consumption: From Individual Behaviours to the Reproduction of Everyday Practices, Time and Soc. 22 (3) (2013) 335-355.

[62] H. Rosa, Social Acceleration: Ethical and Political Consequences of a Desynchronised High-Speed Society, Constellations 10 (1) (2003) 3-33.

[63] J. Palm, Household installation of solar panels - Motives and barriers in a 10-year perspective, Energy Policy 113 (2018) 1-8.

[64] T.H.J. Inderberg, K. Tews, B. Turner, Is there a prosumer pathway? Exploring household solar energy development in Germany, Norway, and the United Kingdom, Energy Res. Social Sci. 42 (2018) 258-269.

[65] Brown, D., Hall, S. and Davis, M.E. (2019) Prosumers in the post subsidy era: an exploration of new prosumer business models in the UK.

[66] B.K. Sovacool, P. Kivimaa, S. Hielscher, K. Jenkins, Vulnerability and resistance in the United Kingdom's smart meter transition, Energy Policy 109 (2017) 767-781.

[67] K. Gram-Hanssen, Standby Consumption Households Analyzed With a Practice Theory Approach, J. Ind. Ecol. 14 (1) (2010) 150-165.

[68] J. Palm, K. Reindl, Understanding energy efficiency in Swedish residential building renovation: A practice theory approach, Energy Res. Social Sci. 11 (2016) 247-255.

[69] I. Bisaga, P. Parikh, To climb or not to climb? Investigating energy use behaviour among Solar Home System adopters through energy ladder and social practice lens, Energy Res. Social Sci. 44 (2018) 293-303.

[70] Shove, E. (2017) Practice theory methodologies do not exist. Available at: https:// practicetheorymethodologies.wordpress.com/2017/02/15/elizabeth-shovepractice-theory-methodologies-do-not-exist/ [Accessed 10 February 2020].

[71] Fylan, F. (2005) Semi-Structured Interviewing. In: Miles, J. and Gilbert, P. (Eds.) A Handbook of Research Methods for Clinical and Health Psychology. Oxford: Oxford University Press: $65-78$.

[72] Adams, W.C. (2015) Conducting Semi-Structured Interviews. In: Newcomer, K.E., Hatry, H.P. and Wholey, J.S. (Eds.) Handbook of Practical Program Evaluation. London: Wiley: $492-505$

[73] M. Hennink, I. Hutter, A. Bailey, Qualitative Research Methods, Sage Publications Ltd, London, 2011.

[74] P. Biernacki, D. Waldorf, Snowball Sampling: Problems and Techniques of Chain Referral Sampling, Sociol. Methods Res. 10 (2) (1981).

[75] Balke, T., Roberts, T., Xenitidou, M. and Gilbert, N. (date unknown) Model Description: Social Practice Model. Available at: http://www.wholesem.ac.uk/ documents/social-practices-documentation [Accessed 10 February 2020].

[76] Kentistos-Rannos, T. and Chatzoglou, P.D. (2017) Comparison Shopping Websites and Their Impact on Consumers' Purchase Intention. In: Kavoura A., Sakas D., Tomaras P. (eds) Strategic Innovative Marketing. Springer Proceedings in Business and Economics. Springer, Cham, 179-185.

[77] B. Boardman, New Directions for Household Energy Efficiency: Evidence from the UK, Energy Policy 32 (2004) 1921-1933.

[78] H. Wilhite, R. Ling, Measured Energy Savings from a more Informative Energy Bill, Energy Build. 22 (1995) 145-155.

[79] G. Brandon, A. Lewis, Reducing Household Energy Consumption: A Qualitative and 
Quantitative Field Study, J. Environ. Psychol. 19 (1999) 75-85.

[80] P. Söderholm, Households' Switching Behaviour between Electricity Suppliers in Sweden, Utility Policy 16 (254-26) (2008) 1.

[81] E. Shove, Efficiency and Consumption: Technology and Practice, Energy Environ. 15 (6) (2004) 1053-1065.

[82] Simmonds, G. (2002) Regulations of the UK Electricity Industry. Centre for the Study of Regulated Industries. Bath: The University of Bath.

[83] J. Burgess, M. Nye, Re-materialising Energy Use through Transparent Monitoring Systems, Energy Policy 36 (12) (2008) 4454-4459.

[84] Huh, S, Y., Woo, J., Lim, S., Lee, Y-G. and Kim, C.S. (2015) What Do Customers Want from Improved Residential Electricity Services? Evidence from a Choice Experiment. Energy Policy 85: 410-420.

[85] Wilson, C.M. and Price, C.W. (2010) Do Consumers Switch to the Best Supplier? Oxford Economic Papers 62 (4): 647-668.

[86] L. Mi, X. Yu, J. Yang, J. Lu, Influence of conspicuous consumption motivation on high-carbon consumption behaviour of Residents - An empirical case study of Jiangsu province, China, J. Cleaner Prod. 191 (2018) 167-178.

[87] D. Clingingsmith, R. Sheremeta, Status and the demand for visible goods: experimental evidence on conspicuous consumption, Exp Econ 21 (2018) 877-904.

[88] M. Yaqoot, P. Diwan, T.C. Kandpal, Review of Barriers to the Dissemination of
Decentralized Renewable Energy Systems, Renew. Sustain. Energy Rev. 58 (2016) 477-490.

[89] Ronayne, D. (2015) Price Comparison Websites. Warwick Economics Research Papers 1056. Warwick: University of Warwick.

[90] S. Agnew, P. Dargusch, Effect of Residential Solar and Storage on Centralized Electricity Supply Systems, Nat. Clim. Change 5 (2015) 315-318.

[91] P. Balcombe, D. Rigby, A. Azapagic, Motivations and Barriers Associated with Adopting Microgeneration Energy Technologies in the UK, Renew. Sustain. Energy Rev. 22 (2013) 655-666.

[92] A.R. Carrico, M. Riemer, Motivating Energy Conservation in the Workplace: An Evaluation of the Use of Group-Level Feedback and Peer Education, J. Environ. Psychol. 31 (1) (2011) 1-13.

[93] M. Khojastehpour, R. Johns, The Effect of Environmental CSR Issues on Corporate/ Brand Reputation and Corporate Profitability, Eur. Bus. Rev. 26 (4) (2014) 330-339.

[94] D. Grewal, G.R. Iyer, R. Krishnan, A. Sharma, The Internet and the price-valueloyalty chain, J. Bus. Res. 56 (5) (2003) 391-398.

[95] A.H. McMakin, E.L. Malone, R.E. Lundgren, Motivating Residents to Conserve Energy without Financial Incentives, Environ. Behav. 34 (6) (2002) 848-863. 